The BDJ News section accepts items that include general news, latest research and diary events that interest our readers. Press releases or articles may be edited, and should include a colour photograph if possible. Please direct your correspondence to the News Editor, Arveen Bajaj at the BDJ, The Macmillan Building, 4 Crinan Street, London N19XW or by email to bdj@bda.org

\section{Selecting student prize winners}

The General Dental Council is inviting each UK dental school, school of dental hygiene and school of dental therapy to nominate a student to receive this year's GDC Prize for Professionalism. The Prize for Professionalism, which is sponsored by the GDC Charitable Trust, recognises the high standards achieved by trainee dental professionals in the UK. It is awarded to students who have demonstrated professionalism in areas such as patient care, clinical governance, team working, communication skills, reliability, integrity and knowledge.

Each school has to decide which of their own students should be awarded this prize and schools are invited to make their nominations by 30 September 2005. The prize is $£ 250$ for dentistry students, £150 for dental therapy students, and £100 for dental hygiene students (the prize money corresponds to the length of the study programmes). The winners from each school will be announced later this year and will be presented with their prize at a special awards' ceremony in December.

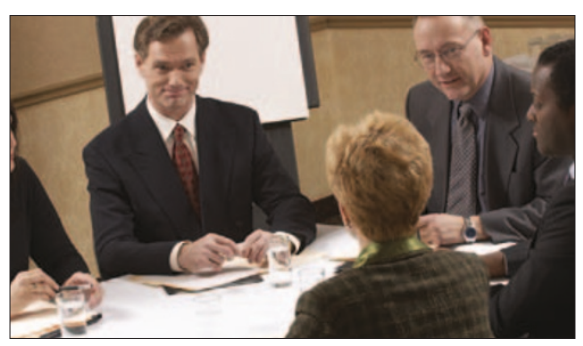

\section{First graduates celebrate achievements}

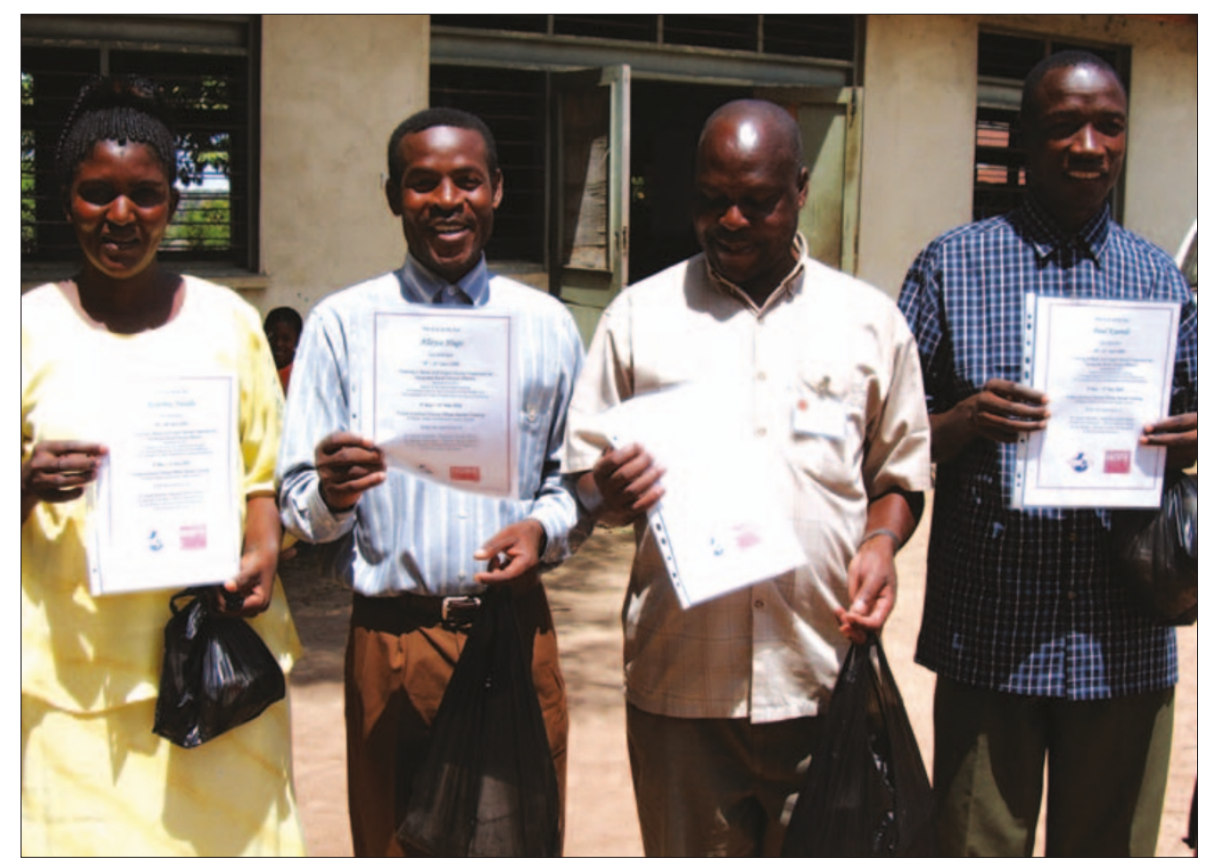

The Bridge2Aid (B2A) Rural Clinical Officer (RCO) Training Programme in Tanzania has produced its first graduates. The graduates, Redemta Natalis, Aloyce Hugo, Jacob Munega and Paul Kisendi spent a further five days being trained one-to-one by volunteer UK dentists in basic extraction techniques. All four passed the basic competencies required at the end of the course, and were allocated B2A instrument kits supplied by Quayle Dental for use in their rural health centres.

B2A believes that the skills the trainees have gained will be invaluable. For example, Paul Kisendi is an RCO in a very remote area approximately $120 \mathrm{~km}$ from Mwanza town. The village where he is based has a small dispensary where he is expected to deliver basic medical services to the surrounding people. Because he is the only medically qualified person, it means he has to do everything - from simple vaccinations to repairing broken limbs. It is hoped that the training, which will run three times a year, will result in more people in rural areas getting treatment. Pictured left to right, the first four RCOs with their certificates, Redemta Natalis, Aloyce Hugo, Jacob Munega and Paul Kisendi.

\title{
Sheffield celebrates pioneering dentist
}

Dental specialists from across the UK came together at the University of Sheffield recently to celebrate the practice of pioneering 19th century Sheffield dentist Frank Harrison, who first recommended the use of the x-ray in everyday dentistry, in 1896.

The occasion was marked by the unveiling of a special blue plaque on the site of his old surgery on Glossop Road, Sheffield, which he used as the base for his local practice in the late 1900s. The plaque was unveiled by Professor Keith Horner, President of the British Society of Dental and Maxillofacial Radiology and was followed by a short talk about Frank Harrison's contribution to British dentistry by Professor Peter Hirschmann, former consultant dental radiologist at the Leeds Dental Institute. Professor Trevor Walsh, Dean of the School of Clinical Dentistry at the University of Sheffield, said: “The University of Sheffield has a proud tradition of teaching excellence in dentistry and it is important for us to commemorate and remember the outstanding work done by our predecessors in the city."

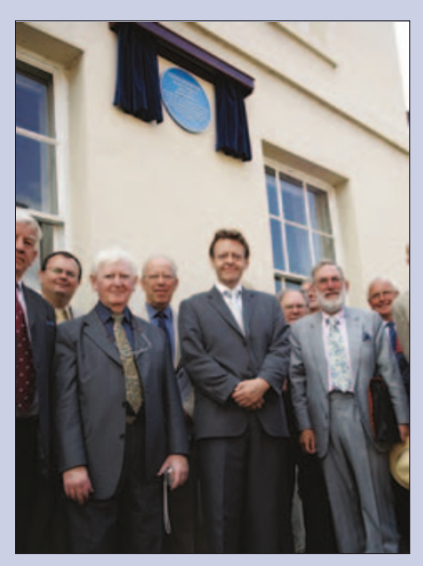




\section{Study measures children's anxiety}

Children rate local anaesthetic and the dentist's drill as the most anxiety-provoking items when visiting the surgery, according to a computerised programme that assesses scales of dental anxiety in children.

The subject is the focus of a study to appear in the next issue of the $B D J$ and looked at the Smiley Faces Program (SFP), a four item computerised trait dental anxiety scale, which uses faces as a response set to assess dental anxiety in children.

The study, Development of a computerised dental anxiety scale for children: validation and reliability, by lecturer in Psychology at the University of Derby, H. Buchanan, involved a sample of 464 children of around 10-years-old from four schools in and around Newcastle-upon-Tyne, Derbyshire and Shropshire.

The SFP included items that were relevant to most children's dental experience (e.g. having a tooth drilled, sitting in the dental waiting room) and used computer graphics to help the child engage with the dental anxiety scale. The computer graphics offered interactive animations, which allowed participants to control aspects of the visual display in a trial and error manner.

It is hoped that the SFP may help encourage dentists to formally assess dental anxiety. Author of the study,
H. Buchanan commented: "The use of computer graphics helped the children engage with the dental anxiety scale, which meant that there were very few missing items. It also means that there is a simple database of children's anxiety scores, so we can identify situations that children are most anxious of, and we can compare anxiety scores across time, and perhaps different treatments".



\section{Salt fluoridation can reduce caries}

Table salt fluoridation can reduce the prevalence of dental caries up to 84 per cent, according to a new book published by the Pan American Health Organization (PAHO) in the USA.

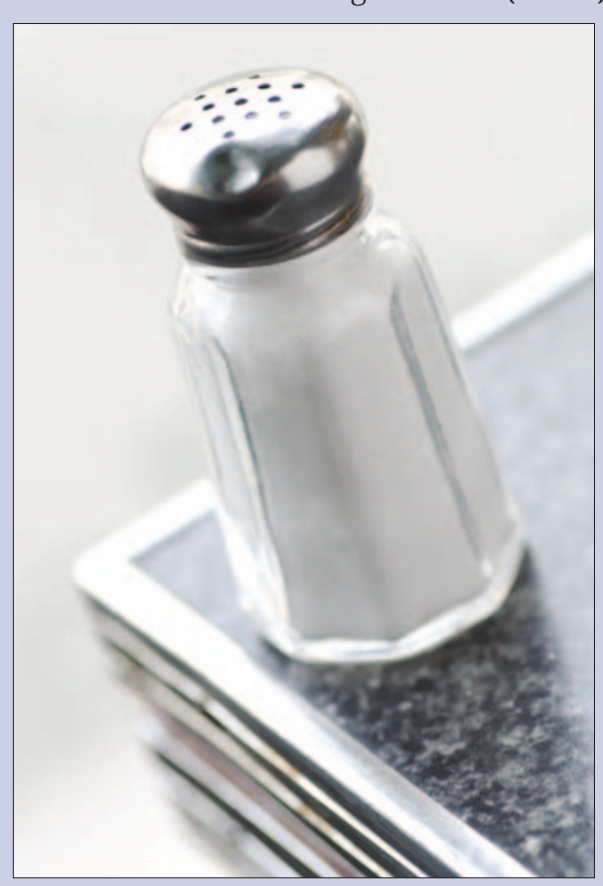

The book, Promoting Oral Health: The Use of Salt Fluoridation to Prevent Dental Caries claims that salt fluoridation programmes over the last decade have placed the countries of the Americas at the leading edge in reducing dental caries, and these programmes are now being replicated in other regions.

"Dental caries is the most common childhood disease and can be avoided thanks to salt fluoridation," said PAHO's Dr. Saskia Estupiñan-Day, regional advisor on oral health and author of the publication. "The Latin American and Caribbean experience is being replicated worldwide. Many countries are seeking our assistance and technical cooperation to implement this greatly beneficial and costeffective public health strategy."

She added that studies on dental caries in 12-year-old-children showed that the average regional rate of caries in the Americas dropped from 5.05 in 1987 to 2.41 in 2004, thanks to salt fluoridation programmes. The most notable reduction took place in Jamaica, a country that achieved an 84 per cent reduction in childhood dental caries in 1995 due to a nationwide salt fluoridation programme started in 1987.

Water fluoridation has been a staple of oral health for decades in North America and the world. However, distribution of fluoride throughout water supply systems in Latin America and the Caribbean is not always the best way to reach people, particularly in remote areas.

The new PAHO book details the history of programmes that have been implemented and the know-how for the salt industries, governments and health professionals still in the developmental phase of salt fluoridation programme implementations.

\section{Entries invited}

The Society for the Advancement of Anaesthesia in Dentistry (SAAD) is inviting entries for the Drummond-Jackson Prize of $£ 1,000$ which is awarded from the proceeds of the Drummond-Jackson Memorial Fund for the most meritorious essay on any subject related to conscious sedation, analgesia, anxiety control or general anaesthesia for dentistry. Open to all dental and medical undergraduates and graduates in the United Kingdom and throughout the world, entries must be received before 31 October 2005 and the winner may be invited to present the paper at an appropriate SAAD scientific meeting. For details visit www.saaduk.org. 


\section{Instrument amnesty launched}

An 'instrument amnesty' is to be launched at this year British Dental Trade Association (BDTA) International Dental Showcase 2005 where dentists can dispose of their unwanted hand instruments. The event is being run by the BDTA and dental charity Dentaid, in order to address the need for dental instruments in developing countries. According to the charity, there is a severe shortage of dentists in developing countries and the ones that are working are drastically under-resourced. The level of care they are qualified to offer is significantly higher than their equipment allows such as no light, no drill, no suction, difficult working conditions and very a limited range of instruments.

Since Dentaid began its work in 1996 more than 120 surgeries have been shipped to projects in over 40 countries and while these surgeries comprise all major items including chairs, lights, x-rays etc which often get the attention due to their size, the most important components are autoclave sterilisers and instruments.

The charity is appealing to dentists for help in order to respond to the overwhelming demand for dental kits and to overcome shortages of certain types of instruments. The dental kits provided overseas by Dentaid have roughly 100 instruments each and the organisation has estimated that if each visitor to Showcase brought at least one instrument each, there would 10,000 available, equivalent to 100 dental kits. This would be enough to supply an instrument kit to the equivalent of every dental professional in Sierra Leone, Malawi, Rwanda, Gambia and Somalia put together, serving a combined population of 37 million people. Certain types of instruments are in shorter supply than others - particularly extraction forceps, elevators, mirrors, scalpel handles and syringes. Instrument donations can be made at the Dentaid stand, located in the entrance area at this year's exhibition, (68 October 2005). Please ensure the instruments donated have been properly sterilised. For more information visit www.dentalshowcase.com.

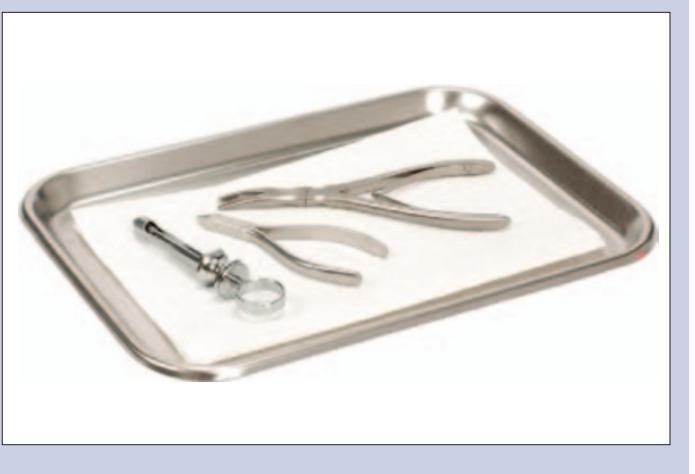

\section{Cash boost to Scottish dentistry}

A £30 million building programme to create up to ten major new dental centres was announced by the Scottish Executive last month. The extra cash will provide a range of dental services and outreach training facilities for students in areas where it is difficult to find an NHS dentist and to develop dental centres and practices across the country. Health Minister Andy Kerr said: "There is no doubt that transforming Scotland's appaling record on oral health will take some time. There is no overnight solution. However, the Action Plan for improving Oral Health and Modernising NHS Dental Services in Scotland supported with investment in new facilities where they are most needed will ensure progress."

The funding for the building programme is part of the $£ 65$ million from the Primary and Community Care Premises Modernisation programme and the money is being made available over 2006-08 to be allocated through NHS Boards bidding to the Executive. NHS Fife received funding of $£ 250,000$ from the 2004-06 Primary and Community Care Premises Modernisation programme towards the Kirkcaldy Dental Access Centre which is due to open at the end of the year.

Andrew Lamb, the British Dental Association's Director for Scotland, welcomed the news but warned that the extra funding should be targeted at patient care, rather than administration. "The announcement of funding for primary care rightly places an

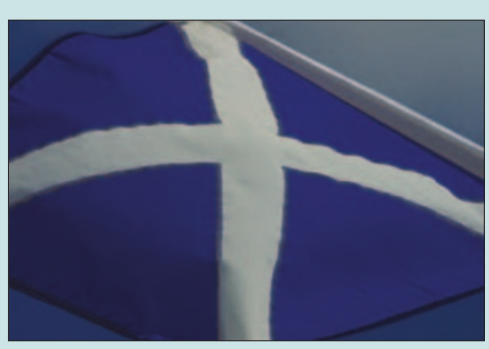
emphasis on dentistry. Scotland has a depressing oral health record, and tackling the significant problem patients experience accessing NHS dental care must be a priority.

While any extra funding in NHS dentistry is a step in the right direction, the British Dental Association nonetheless believes that further investment in high street dentistry remains necessary if the service is to fulfil its potential."

\section{DIARY}

September 2005

The Irish Endodontic Society 12th Biennial

Congress of the European Society of

Endodontology

Date: 15-17.09.05

Venue: Dublin

Tel: +35316799144

Fax: +35316486197

www.esedublin2005.com

\section{October 2005}

BDA Metropolitan Branch: Spot the Composite

Date: 01.10 .05

Venue: British Dental Association, London Tel: 01943604400

British Dental Trade Association International Dental Showcase 2005

Date: 06-08.10.05

Venue: NEC Birmingham

Tel: 08702413365

www.dentalshowcase.com

146th American Dental Association Annual Session and Technical Exhibition

Date: 06-09.10.05

Venue: Pennsylvania Convention Center, Philadelphia

Email: annualsession@ada.org

www.ada.org

BDA North of Scotland Branch Young

Dentists Conference

Date: 22.10.05

Venue: Dundee Dental Hospital and School, and the Apex Hotel and Spa, Dundee

Contact: Frankie Soldani

Tel: 01382635962

DenTech China 2005

Date: 26-29.10.05

Venue: Shanghai Everbright Convention \&t Exhibition Center, Shanghai

Tel: 86-21-6294 6966

Fax: 86-21-6280 0908

Email:mail@showstar.net www.dentech.com.cn

November 2005

2nd European Congress on the Reconstruction of the Periodontally Diseased Patient

Date: 25-27.11.05

Venue: Radisson SAS Scandinavia Hotel, Copenhagen

Email: kongress@quintessenz.de www.quintessenz.de/ecrp

Greater New York Dental Meeting

Date: 25-30.11.05

Venue: New York

Email: info@gnydm.com

www.gnydm.com 


\section{Healthy hearts and gums}

Healthy heart habits can have positive benefits for oral health too, according to a study published in the American Academy of Periodontology's Journal of Periodontology. Researchers from Case Western Reserve University in Cleveland, Ohio, examined data from over 12,000 individuals who participated in the third National Health and Nutrition Examination Survey (NHANES III) and found that individuals who exercised, had healthy eating habits and maintained a normal weight were 40 percent less likely to develop periodontitis.

The findings were reported in the article, Periodontitis and Three Health-Enhancing Behaviors: Maintaining Normal Weight, Engaging in Recommended Level of Exercise and Consuming a High-Quality Diet. Beside healthy brushing and flossing habits, prior to this study other healthy behaviours that contribute to the prevention of the disease were unknown, according to the researchers Mohammad S. Al-Zahrani, Elaine A. Borawski and Nabil F. Bissada. The study found that the prevalence of periodontitis was reduced by 29 per cent for those individuals who only met two of the healthy behaviours and 16 per cent in those that met at least one.

The authors claimed that advances in dental medicine have permitted more people to keep their teeth as they grow older and that understanding the underlying ways to prevent gum diseases have become increasingly important. Curious whether the same factors that can prevent heart disease and lower the risks for diabetes might also impact oral health, they examined the cumulative relationship between weight, exercise and a high-quality diet and dental disease in the United States population.

They concluded that the healthy behaviours such as exercise and diet that lower the risks of diabetes can also lower the risk factors for periodontitis. Exercise was also known to reduce the C-reactive protein in the blood associated with inflammation in the heart and periodontal disease. Healthy eating habits, which build the body's defences against disease, also reduce the production of plaque biofilm, which is the primary epidemiological factor associated with periodontal disease.

Conquering periodontal disease, according to the researchers, may mean more than just targeting the disease but addressing multiple risk behaviours, and since oral health professionals may see their patients two or four times a year, it gives them several opportunities to promote these healthy behaviours.

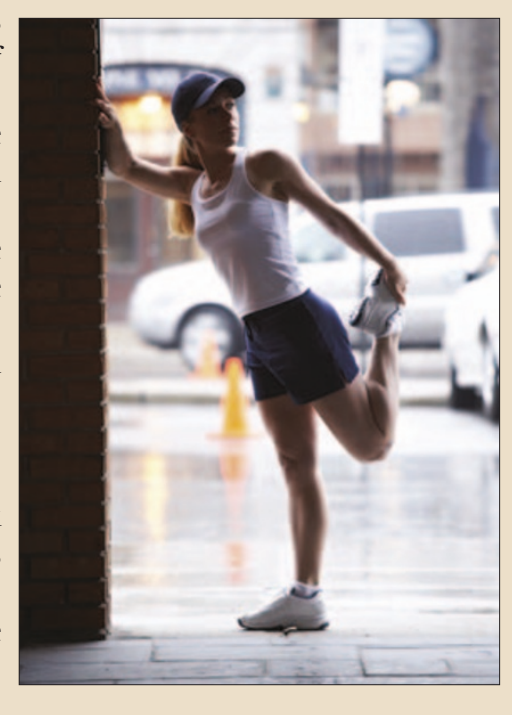

\section{Targeting high caries areas}

The BDA and Colgate Oral Health Month campaign which is running throughout September includes outreach sampling programmes in areas of high caries in five-yearold children. Colgate, along with the BDA, utilised the latest British Association for the Study of Community Dentistry (BASCD) data for five-year-olds to identify 15 areas to be used in the 2005 campaign.

BASCD surveys measure the dental caries experience of five and 14-year-old children in England and Wales. These programmes monitor the dental health of children and contribute to the national monitoring service provision and targets, while providing data locally to aid in service planning and the evaluation of local oral health strategy targets.

The campaign will deliver key oral health messages to patients in partnership with UK dental professionals such as to brush teeth twice a day with fluoride toothpaste, change toothbrushes every three months, make regular dental visits and try to avoid sugary foods, especially between meals. The initiative, now in its fourth year, will give dental professionals the opportunity to get involved in a nationwide campaign that will be supported by TV advertising. In order to promote improved oral health habits Colgate will also distribute educational materials and over one million oral care products in areas with the highest levels of caries.

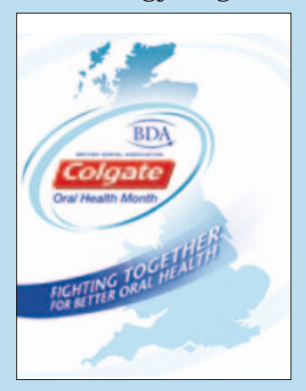

